\title{
openheart Functional assessment of myocardial ischaemia by intracoronary ECG
}

\author{
Marius Reto Bigler (1D , Michael Stoller, Fabien Praz, George C M Siontis, \\ Raphael Grossenbacher, Christine Tschannen, Christian Seiler
}

To cite: Bigler MR, Stoller M, Praz F, et al. Functional assessment of myocardial ischaemia by intracoronary ECG. Open Heart 2021;8:e01447. doi:10.1136/ openhrt-2020-001447

Received 14 September 2020 Revised 17 November 2020 Accepted 17 December 2020

Check for updates

(C) Author(s) (or their employer(s)) 2021. Re-use permitted under CC BY-NC. No commercial re-use. See rights and permissions. Published by BMJ.

Cardiology, Inselspital University Hospital Bern, Bern, Switzerland

Correspondence to Professor Christian Seiler; christian.seiler@insel.ch

\begin{abstract}
Introduction In patients with chronic coronary syndrome, percutaneous coronary intervention targets haemodynamically significant stenoses, that is, those thought to cause ischaemia. Intracoronary ECG (icECG) detects ischaemia directly where it occurs. Thus, the goal of this study was to test the accuracy of icECG during pharmacological inotropic stress to determine functional coronary lesion severity in comparison to the structural parameter of quantitative angiographic per cent diameter stenosis (\%S), as well as to the haemodynamic indices of fractional flow reserve (FFR) and instantaneous wave-free ratio (iFR).
\end{abstract}

Method The primary study endpoint of this prospective trial was the maximal change in icECG ST-segment shift during pharmacological inotropic stress induced by dobutamine plus atropine obtained within $1 \mathrm{~min}$ after reaching maximal heart rate $(=220$-age). IcECG was acquired by attaching an alligator clamp to the angioplasty guidewire positioned downstream of the stenosis. For the pressure-derived stenosis severity ratios, coronary perfusion pressure and simultaneous aortic pressure were continuously recorded.

Results There was a direct linear relation between icECG ST-segment shift and \%S: icECG $=-0.8+0.03 * \%$ S $\left(r^{2}=0.164 ; p<0.0001\right)$. There were inverse linear correlations between FFR and $\% \mathrm{~S}$ : FFR $=1.1-6.1^{*} 10$ $3^{\star} \% \mathrm{~S}\left(\mathrm{r}^{2}=0.494 ; \mathrm{p}<0.0001\right)$, and between iFR and $\% \mathrm{~S}$ : $\mathrm{iFR}=1.27-8.6^{*} 10-3^{*} \% \mathrm{~S}\left(\mathrm{r}^{2}=0.461 ; p<0.0001\right)$. Using a \%S-threshold of $\geq 50 \%$ as the reference for structura stenosis relevance, receiver operating characteristicsanalysis of absolute icECG ST-segment shift during hyperemia showed an area under the curve (AUC) of $0.678 \pm 0.054(p=0.002$; sensitivity $=85 \%$, specificity $=50 \%$ at $0.34 \mathrm{mV})$. AUC for FFR was $0.854 \pm 0.037(\mathrm{p}<0.0001$; sensitivity $=64 \%$, specificity $=96 \%$ at 0.78 ), and for iFR it was $0.816 \pm 0.043(\mathrm{p}<0.0001 ;$ sensitivity $=62 \%$, specificity $=96 \%$ at 0.83 ).

Conclusions Hyperaemic icECG ST-segment shift detects structurally relevant coronary stenotic lesions with high sensitivity, while they are identified highly specific by FFR and iFR.

\section{INTRODUCTION}

In patients with chronic coronary syndrome (CCS), percutaneous coronary intervention (PCI) targets haemodynamically relevant stenotic lesions, that is, those thought to cause ischaemia. That is, coronary lesions inducing

\section{Key questions}

What is already known about this subject?

- Diagnostic assessment of functional stenosis relevance by coronary pressure measurement (that is, fractional flow reserve, instantaneous wave-free ratio) has been shown to be efficacious on patient outcome.

- Intracoronary ECG provides a direct measure of myocardial ischaemia in real time, and thus, is useful to predict postprocedural myocardial injury.

What does this study add?

- The theoretical stenosis-specificity of the pressurederived functional indices was directly corroborated for the first time in clinical practice.

- Hyperaemic intracoronary ECG ST-segment shift detects structurally relevant coronary stenotic lesions with high sensitivity

How might this impact on clinical practice?

- In a selected population, intracoronary ECG can act as a high-sensitivity rule out test for relevant stenosis severity.

flow restrictions beyond the compensatory autoregulation of the myocardial microcirculation under stress conditions. This key feature of coronary resistance, and thus, myocardial perfusion normally allows a fourfold to fivefold blood flow increase ${ }^{1}$ (that is, coronary flow reserve, CFR), respectively, is responsible for maintaining constant resting myocardial perfusion of $1 \mathrm{~mL}$ blood per minute per gram over a broad range of arterial perfusion pressures. Hence in patients with CCS, compensatory coronary vasodilatation preserves adequate perfusion at the expense of decreased CFR. Accordingly, in situations with higher oxygen demand, for example, during physical exercise, the limited vasodilatory reserve causes ischaemia. Gould and Lipscomb ${ }^{2}$ were the first to investigate these coronary pathophysiologic mechanisms. Based on their findings, coronary angiographic lesion severity of $\geq 50 \%$ diameter narrowing has been extensively used as the relevant threshold for PCI. 


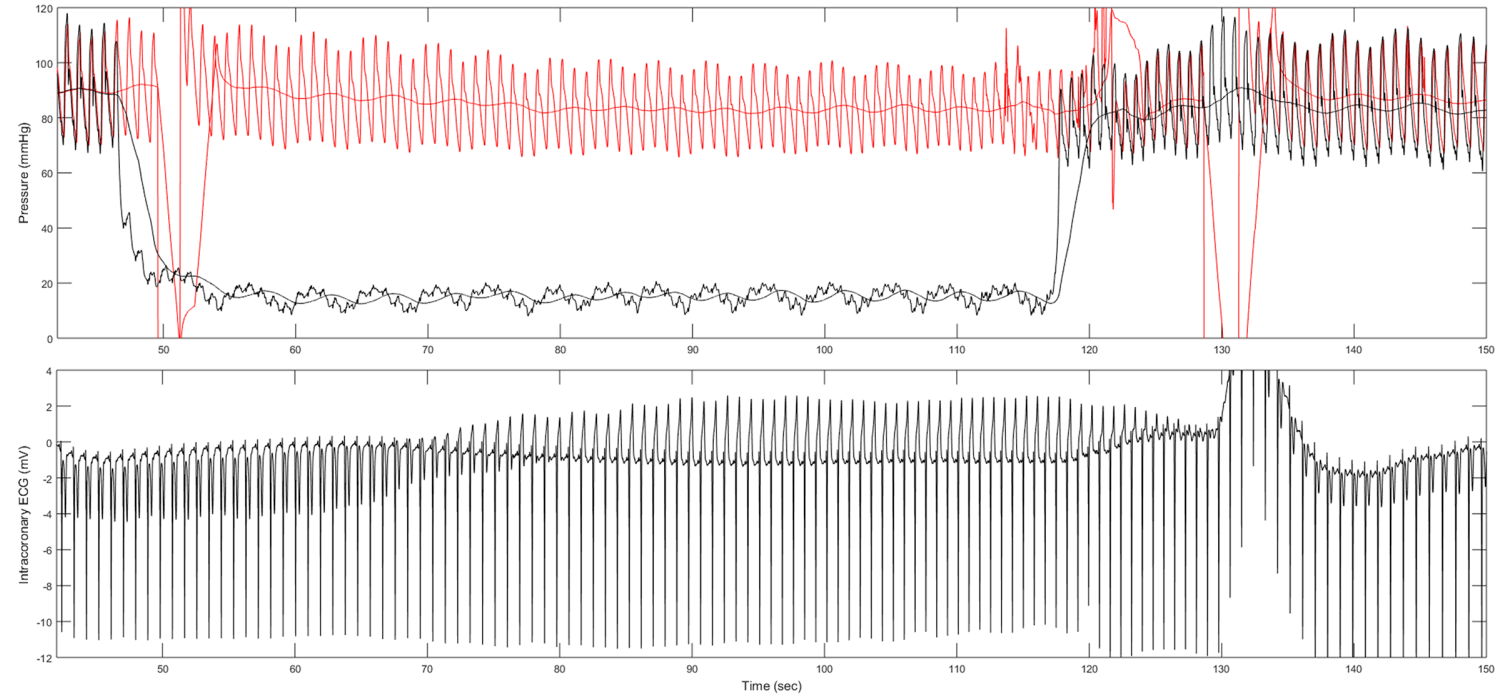

Figure 1 Collateral flow index measurement for the induction of reactive hyperaemia. Simultaneous recordings of mean and phasic aortic (upper panel, red signals), coronary occlusive pressure (upper panel, black signals) and intracoronary ECG (lower panel, icECG). Fractional flow reserve during reactive hyperaemia is calculated immediately after the 1 min occlusion, followed by angiography (marked by the outlier of the red pressure signal).

Compared with the structural, mostly visual angiographic approach, diagnostic assessment of functional stenosis relevance by coronary pressure measurement has been suggested to affect patient outcome. ${ }^{3}$ In comparison to direct measurement of coronary blood flow reserve, coronary pressure measurements are more robust. Given temporary paralysis of the coronary microcirculation, pressure is, theoretically, directly related to coronary flow. ${ }^{4}$ Thus, the pressure drop across a coronary stenosis, that is, fractional flow reserve $\left(\mathrm{FFR}^{5}\right)$, respectively, instantaneous wave-free ratio $\left(\mathrm{iFR}^{67}\right)$ provides an estimate of its restrictive effect on flow. However and despite their prognostic value derived from large randomised clinical trials, both FFR and iFR rely on the, so far, untested concept of their being stenosis-specific, ${ }^{5}$ and not stenosis-plus microcirculatory-specific, the fact of which limits their usefulness in defining a true ischaemic threshold.

Conversely, intracoronary ECG (icECG) provides a direct measure of myocardial ischaemia in real time ${ }^{8-11}$ (figure 1). Hence, the goal of this study was to test the amount of myocardial ischaemia by icECG during inotropic stress for coronary lesion severity assessment in comparison to structural quantitative stenosis severity $(\% \mathrm{~S})$, and to established haemodynamic indices for lesion severity (FFR, iFR).

\section{METHODS}

\section{Study design and patients}

This was a prospective observational study in 100 patients with CCS undergoing diagnostic coronary angiography due to chest pain. The primary study endpoint was the maximal change in icECG ST-segment shift during pharmacological inotropic stress induced by dobutamine plus atropine obtained within 1 min after reaching maximal heart rate in beats per minute $(=220$-age $)$. Secondary study endpoints were $\% \mathrm{~S}$ using biplane quantitative coronary angiography, and the pressure-derived haemodynamic indices FFR and iFR. Criteria for study inclusion were age $>18$ years, and written informed consent for study participation. Exclusion criteria were acute coronary syndrome, severe aortic stenosis, prior myocardial infarction in the vascular territory undergoing study measurement, presence of left bundle branch block, presence or history of non-sinus rhythm or paced rhythm, contraindication to pharmacological inotropic stress as well as severe hepatic or renal failure (creatinine clearance $<15 \mathrm{~mL} / \mathrm{min} / 1.73 \mathrm{~m}^{2}$ ).

All patients gave written informed consent before the start of the study procedure.

\section{Cardiac catheterisation and quantitative coronary angiography}

Patients underwent left heart catheterisation and coronary angiography for diagnostic purposes from the right radial artery approach via a 6 -in- $5 \mathrm{~F}$ introducer sheath. Biplane coronary angiography was performed followed by left ventriculography. Coronary artery stenoses were assessed quantitatively in two orthogonal planes as per cent diameter narrowing $(\% \mathrm{~S})$ using the guiding catheter for calibration. In the situation of serial coronary lesions, $\% \mathrm{~S}$ of the most severe stenosis was calculated.

\section{Acquisition of the icECG}

IcECG was acquired by attaching an alligator clamp to the 0.014-inch pressure monitoring angioplasty guidewire (PressureWire X Guidewire, Abbott, Chicago, Illinois, USA) positioned downstream of the stenosis, and connecting it to a precordial lead generating a pseudounipolar lead between Wilson Central Terminal and the pressure sensor. Due to the structure of the pressure guidewire with integrated isolation, isolating the guidewire 


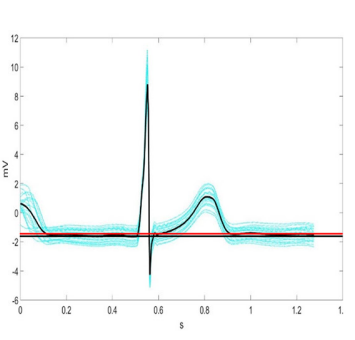

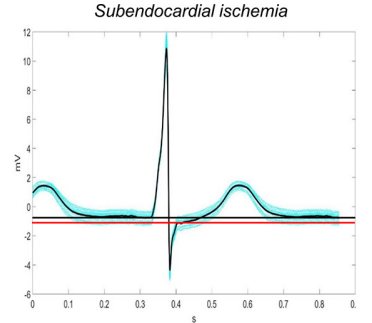

+2min: $110 \mathrm{bpm}, \mathrm{ST}$-shift: $-0.36 \mathrm{mV}$

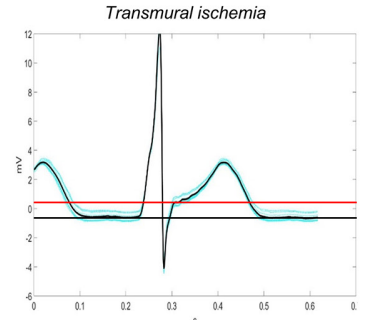

$\rightarrow \quad+\underline{7 m i n}: 152 b p m$, ST-shift: $+1.05 \mathrm{mV}$

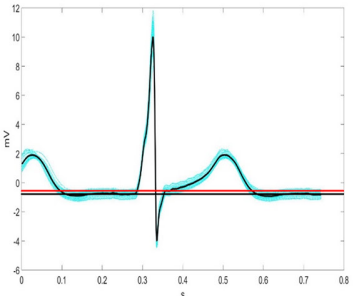

$\rightarrow \quad+4 \mathrm{~min}: 127 \mathrm{bpm}, \mathrm{ST}$-shift: $+0.27 \mathrm{mV}$

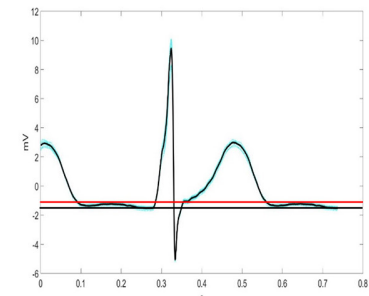

$\rightarrow \quad+$ gmin: $127 \mathrm{bpm}$, ST-shift: $+0.45 \mathrm{mV}$

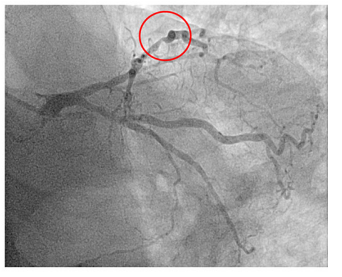

LAO $0^{\circ}$, Caudal $41^{\circ}$

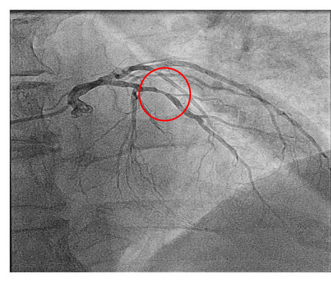

LAO $0^{\circ}$, Caudal $0^{\circ}$

\%S: 68 |FFR: 0.66 | iFR: 0.76

Figure 2 Pharmacological inotropic stress test with recording of intracoronary ECG (icECG). With increasing heart rate and myocardial oxygen consumption, flow impairment of the coronary lesion causes first subendocardial and later transmural myocardial ischaemia with a positive icECG ST-segment shift. Turquoise=IcECG of a single heartbeat, black=signal-averaged icECG of at least 12 consecutive QRS-complexes, \%S, per cent diameter stenosis; FFR, fractional flow reserve; iFR, instantaneous wave-free ratio.

also proximally was not required. ${ }^{11}$ IcECG recording was performed at a sampling frequency of $2000 \mathrm{~Hz}$, and with standard system filtering (corresponding to a bandpassfilter $0.05-100 \mathrm{~Hz}$ ). The primary study endpoint, maximal change in icECG ST-segment shift obtained within 1 min after reaching maximal heart rate was measured $60 \mathrm{~ms}$ after the J-point on 10-15 consecutive and signal-averaged QRS-complexes (figure 2).

\section{Assessment of pressure-derived haemodynamic indices}

For the pressure-derived ratios FFR and iFR, distal coronary artery pressure $\left(\mathrm{P}_{\mathrm{d}}, \mathrm{mm} \mathrm{Hg}\right)$ and aortic pressure $\left(\mathrm{P}_{\mathrm{ao}}\right.$, $\mathrm{mm} \mathrm{Hg}$ ) were continuously recorded. FFR, defined as 'the ratio of maximal blood flow downstream of a stenosis relative to unimpaired maximal blood flow $\left(=\right.$ meanP $_{\mathrm{d}} /$ meanP $\mathrm{ao}_{\mathrm{a}}$ ) during hyperaemia ${ }^{5}$ was calculated continuously during pharmacologic inotropic stress. In addition, to receive an independent reference method for the assessment of stenosis severity, FFR was also determined during reactive hyperaemia. Hyperaemia was induced by a 1 min proximal coronary artery balloon occlusion in the vessel of interest (figure 1) immediately followed by angiography. This method has been previously validated against $\mathrm{FFR}_{\text {adenosine' }}{ }^{12}$ and it allowed also the determination of collateral flow index (CFI), defined as mean coronary occlusive pressure relative to mean aortic pressure, both subtracted by central venous pressure. ${ }^{1314}$

IFR was calculated offline according to the proposed method of Sen $e t a t^{6}$ as the pressure ratio $\mathrm{P}_{\mathrm{d}} / \mathrm{P}_{\mathrm{ao}}$ in the so called diastolic wave-free period. During this period, that is, beginning $25 \%$ of diastolic duration (ms) after the dicrotic notch of the phasic aortic pressure curve, and ending $5 \mathrm{~ms}$ before the start of the next ECG QRS complex, coronary resistance is thought to be stable and minimal. ${ }^{6}$

\section{Study protocol}

Immediately following right radial artery sheath insertion, 5'000 units of intravenous heparin plus two puffs of oral isosorbidedinitrate were given. Following diagnostic coronary angiography, the 0.014 inch pressure monitoring angioplasty guidewire was set at zero, calibrated, advanced through the guiding catheter, and positioned in the distal part of the vessel downstream of the coronary stenosis. Special care was taken to ensure the position of the guidewire in the main vessel to exclude the possibility of coronary side branch occlusion. Before start of pharmacologic inotropic stress, flushing of the catheter with $15 \mathrm{~mL}$ of saline allowed the recording of unsmoothed aortic and coronary pressure signals necessary for the calculation of iFR. Immediately after recording of iFR, pharmacological inotropic stress test using intravenous dobutamine at a rate of $20 \mu \mathrm{g} / \mathrm{kg} / \mathrm{min}$ was started for $2 \mathrm{~min}$, followed by $4 \mathrm{~min}$ of intravenous dobutamine at a rate of $40 \mu \mathrm{g} / \mathrm{kg} / \mathrm{min}$. To prevent cardiac preload reduction, that is, a conventional side effect of dobutamine, continuous infusion of saline was maintained throughout the study procedure. If the maximal heart rate $(=220$ -age) was not reached after $6 \mathrm{~min}, 0.5-1 \mathrm{mg}$ of intravenous atropine was given. At maximal heart rate, infusion of dobutamine was maintained for another minute to allow for full development of ischaemia. Afterwards, dobutamine was stopped, and esmolol (10 $\mathrm{mg}$ stepwise) was given to slow down the heart rate. During the entire procedure, continuous recording of the icECG, $\mathrm{P}_{\mathrm{d}}$ and $\mathrm{P}_{\text {ао }}$ was performed. 
After normalisation of heart rate, an adequately sized angioplasty balloon catheter was positioned in the ostial part of the vessel of interest. Coronary balloon inflation for measurement of CFI and induction of reactive hyperaemia occurred at an inflation pressure of 1-2 atmospheres for exactly $1 \mathrm{~min}$. Complete coronary occlusion was confirmed by angiography. Immediately after balloon deflation, reactive hyperaemia, that is, postocclusive FFR was obtained following angiography.

Treatment of the coronary lesion was independent of the study results, and at the discretion of the interventional cardiologist.

\section{Statistical analysis}

For the purpose of data presentation, two study groups were formed based on $\% \mathrm{~S}$ (<or $\geq 50 \%)$. Between-group comparison of continuous demographic variables and haemodynamic parameters was performed by an unpaired Student's t-test.

Linear regression analysis was performed for univariate association testing between icECG ST-segment shift and secondary study endpoints. Non-parametric receiver operating characteristics (ROC) curve analysis was used for accuracy assessment of detecting a $\% \mathrm{~S}$ of $\geq 50 \%$ defining coronary structural stenosis significance by icECG ST-segment shift, FFR and iFR. Comparison of the area under the ROC curve was performed using the DeLong-Test.

Statistical significance was defined at a $\mathrm{p}<0.05$. Continuous variables are given as mean $\pm \mathrm{SD}$. All analyses were performed using SPSS V.25 (IBM Statistics) or MedCalc for Windows, V.19.1 (MedCalc Software, Ostend, Belgium).

\section{RESULTS}

One hundred patients were included in the study. Using the $\% \mathrm{~S}$ threshold of $\geq 50 \%$ as definition for structural significance, 52 patients were in the group with a significant coronary stenosis.

\section{Patient characteristics}

There was no significant difference between the groups in terms of age, sex, body mass index or cardiovascular risk factors (table 1). There was a significant difference between the groups in Canadian cardiovascular society class, demonstrating a higher level of symptoms in patients with a significant coronary lesion. Regarding

\begin{tabular}{|c|c|c|c|c|}
\hline & Overall & $\% \mathrm{~S}<50 \%$ & $\% \mathbf{S} \geq 50 \%$ & p-value \\
\hline No of patients & 100 & 48 & 52 & - \\
\hline \multicolumn{5}{|l|}{ Patient characteristics } \\
\hline Age & $66 \pm 11$ & $67 \pm 10$ & $66 \pm 11$ & 0.623 \\
\hline Female gender, $\mathrm{n}(\%)$ & $25(25)$ & $15(31)$ & $10(19)$ & 0.176 \\
\hline Height (cm) & $174 \pm 8$ & $174 \pm 8$ & $174 \pm 8$ & 0.803 \\
\hline Weight (kg) & $84 \pm 16$ & $85 \pm 17$ & $83 \pm 15$ & 0.627 \\
\hline Body mass index $\left(\mathrm{kg} / \mathrm{m}^{2}\right)$ & $28 \pm 5$ & $28 \pm 5$ & $27 \pm 4$ & 0.523 \\
\hline Angina pectoris before intervention (\%) & 53 & 58 & 48 & 0.324 \\
\hline Duration of angina pectoris (months) & $9 \pm 21$ & $6 \pm 6$ & $13 \pm 30$ & 0.414 \\
\hline Canadian cardiovascular society class of angina pectoris & $2.10 \pm 1.05$ & $1.67 \pm 0.83$ & $2.56 \pm 1.12$ & 0.002 \\
\hline Diabetes mellitus (\%) & 23 & 21 & 25 & 0.643 \\
\hline Arterial hypertension (\%) & 69 & 67 & 71 & 0.670 \\
\hline Current smoking (\%) & 12 & 8 & 15 & 0.362 \\
\hline Cumulative pack years of cigarettes & $38 \pm 21$ & $36 \pm 20$ & $40 \pm 24$ & 0.664 \\
\hline Dyslipidaemia (\%) & 73 & 75 & 71 & 0.822 \\
\hline Family history for coronary artery disease (\%) & 32 & 33 & 31 & 0.832 \\
\hline Prior myocardial infarction (\%) & 37 & 29 & 44 & 0.148 \\
\hline \multicolumn{5}{|l|}{ Medical treatment } \\
\hline Aspirin (\%) & 87 & 83 & 90 & 0.377 \\
\hline Platelet inhibitor (\%) & 43 & 38 & 48 & 0.317 \\
\hline Calcium channel-blocker (\%) & 27 & 31 & 23 & 0.377 \\
\hline Beta-blocker (\%) & 51 & 42 & 60 & 0.109 \\
\hline Nitrate $(\%)$ & 12 & 15 & 10 & 0.544 \\
\hline Oral anticoagulation (\%) & 7 & 6 & 8 & 1.000 \\
\hline Statin (\%) & 77 & 77 & 77 & 1.000 \\
\hline ACE-inhibitor or ARB (\%) & 71 & 63 & 79 & 0.082 \\
\hline Diuretics (\%) & 28 & 33 & 23 & 0.274 \\
\hline
\end{tabular}

$\mathrm{ACE}$, angiotensin-converting enzyme; ARB, angiotensin receptor blocker. 
Coronary artery disease

\begin{tabular}{|c|c|c|c|c|}
\hline & Overall & $\% S<50 \%$ & $\% S \geq 50 \%$ & $\mathrm{p}$-value \\
\hline Heart rate (beats per minute) & $77 \pm 16$ & $76 \pm 20$ & $78 \pm 12$ & 0.545 \\
\hline Systolic blood pressure (mm Hg) & $122 \pm 21$ & $121 \pm 20$ & $124 \pm 22$ & 0.540 \\
\hline Diastolic blood pressure $(\mathrm{mm} \mathrm{Hg})$ & $66 \pm 12$ & $66 \pm 11$ & $67 \pm 12$ & 0.578 \\
\hline Left ventricular end-diastolic pressure $(\mathrm{mm} \mathrm{Hg})$ & $11 \pm 6$ & $11 \pm 6$ & $11 \pm 6$ & 0.898 \\
\hline Left ventricular ejection fraction (\%) & $63 \pm 8$ & $64 \pm 7$ & $63 \pm 8$ & 0.552 \\
\hline \multicolumn{5}{|l|}{ Coronary angiographic parameters } \\
\hline No of diseased vessels & $1.81 \pm 0.94$ & $1.50 \pm 0.99$ & $2.10 \pm 0.84$ & 0.001 \\
\hline No of coronary lesions (visually relevant) & $1.83 \pm 1.60$ & $1.21 \pm 1.21$ & $2.38 \pm 1.68$ & $<0.001$ \\
\hline \multicolumn{5}{|l|}{ Target vessel distribution } \\
\hline Left anterior descending, $\mathrm{n}$ & 55 & 23 & 32 & 0.362 \\
\hline Left circumflex coronary artery, $n$ & 24 & 14 & 10 & \\
\hline Right coronary artery, $\mathrm{n}$ & 21 & 11 & 10 & \\
\hline \multicolumn{5}{|l|}{ Study parameters } \\
\hline Maximum heart rate achieved (beats per minute) & $150 \pm 16$ & $149 \pm 18$ & $151 \pm 13$ & 0.508 \\
\hline Maximal heart rate in \% of theoretical maximal heart rate (220-age) & $98 \pm 11$ & $98 \pm 12$ & $98 \pm 10$ & 0.705 \\
\hline Quantitative coronary angiography of the lesion of interest (\%) & $53 \pm 17$ & $39 \pm 6$ & $66 \pm 12$ & - \\
\hline Fractional flow reserve & $0.798 \pm 0.143$ & $0.887 \pm 0.073$ & $0.716 \pm 0.143$ & $<0.001$ \\
\hline Instantaneous wave-free ratio & $0.812 \pm 0.209$ & $0.922 \pm 0.052$ & $0.710 \pm 0.245$ & $<0.001$ \\
\hline $\begin{array}{l}\text { Intracoronary ECG ST-segment shift measured @ J-Point +60 ms (mV) } \\
\text { within } 1 \text { min after maximal heart rate }\end{array}$ & $0.965 \pm 1.324$ & $0.545 \pm 0.892$ & $1.352 \pm 1.533$ & 0.002 \\
\hline Collateral flow index & $0.118 \pm 0.100$ & $0.083 \pm 0.070$ & $0.148 \pm 0.113$ & 0.001 \\
\hline
\end{tabular}

cardiovascular medication, there was no difference between the groups.

\section{Haemodynamic and coronary angiography data}

There was no significant difference between the groups in basic haemodynamic parameters, that is, heart rate at rest, left ventricular ejection fraction or arterial blood pressure. Patients with a $\% \mathrm{~S} \geq 50 \%$ showed a higher number of structurally relevant stenoses on coronary angiogram (table 2).

Left anterior descending artery served more often as the study vessel than other coronary arteries; maximum heart rate was similar between the groups. Overall, $\% \mathrm{~S}$, FFR and iFR were equal to $53 \pm 17,0.789 \pm 0.143$, and $0.812 \pm 0.209$, respectively.

There was a direct linear relation between icECG ST-segment shift and \%S: icECG $=-0.8+0.03 * \% \mathrm{~S}$ $\left(r^{2}=0.164 ; p<0.001\right.$, figure 3$)$. There were inverse linear correlations between FFR and $\% \mathrm{~S}$ : FFR $=1.1-6.1 * 10^{-3} * \% \mathrm{~S}$ $\left(r^{2}=0.494 ; p<0.001\right.$, figure 4$)$, and between iFR and $\% \mathrm{~S}$ : iFR $=1.27-8.6 * 10^{-3} * \% \mathrm{~S}\left(\mathrm{r}^{2}=0.461 ; \mathrm{p}<0.001\right.$, figure 4$)$.

Using a $\% \mathrm{~S}$ threshold of $\geq 50 \%$ as the reference for structural stenosis relevance, ROC-analysis of absolute icECG ST-segment shift showed an area under the curve (AUC) of $0.678 \pm 0.054(\mathrm{p}=0.002)$. AUC for FFR was $0.854 \pm 0.037(\mathrm{p}<0.0001)$, and for iFR it was $0.816 \pm 0.043$ $(\mathrm{p}<0.0001$, figure 5$)$.

The DeLong-Test of the ROC-curves showed a significant difference for FFR and iFR as compared with icECG ST-segment shift $(\mathrm{p}=0.002$, respectively $\mathrm{p}=0.024)$. There was no relevant difference in AUC between FFR and iFR $(\mathrm{p}=0.3151)$.

Regarding the optimum cut-off for icECG, an absolute ST-segment shift of $0.34 \mathrm{mV}$ (taken $60 \mathrm{~ms}$ after the J-point) distinguished best between haemodynamically relevant and irrelevant stenotic lesions; sensitivity $85 \%$, specificity $50 \%$.

The best cut-off point for FFR to detect a $\% \mathrm{~S} \geq 50 \%$ was 0.78 (sensitivity $64 \%$, specificity $96 \%$ ). For iFR, the best cut-off point was 0.83 (sensitivity $62 \%$, specificity $96 \%$ ).

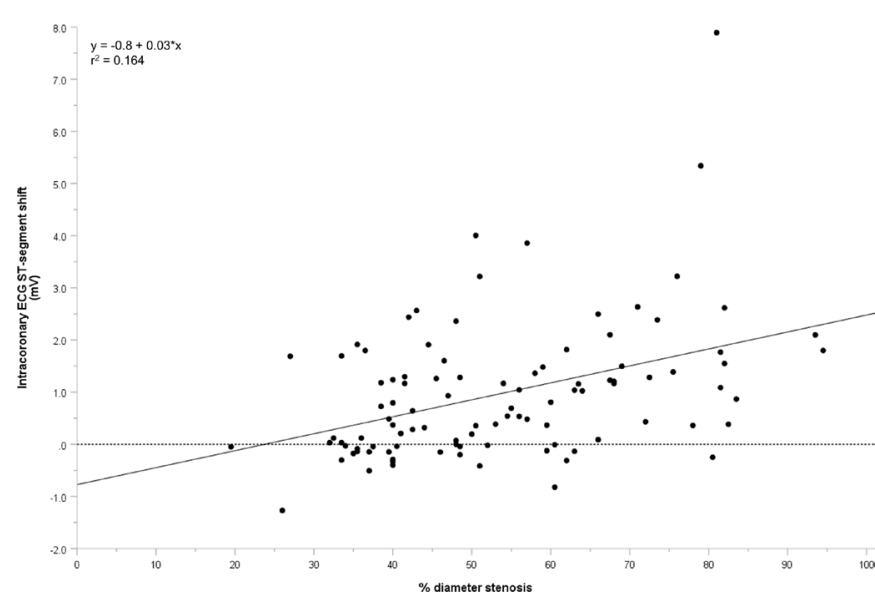

Figure 3 Linear regression between intracoronary ECG (icECG) ST-segment shift and per cent diameter coronary stenosis. solid line=regression line; dashed line=marker for $0 \mathrm{mV}$ icECG ST-segment shift. 

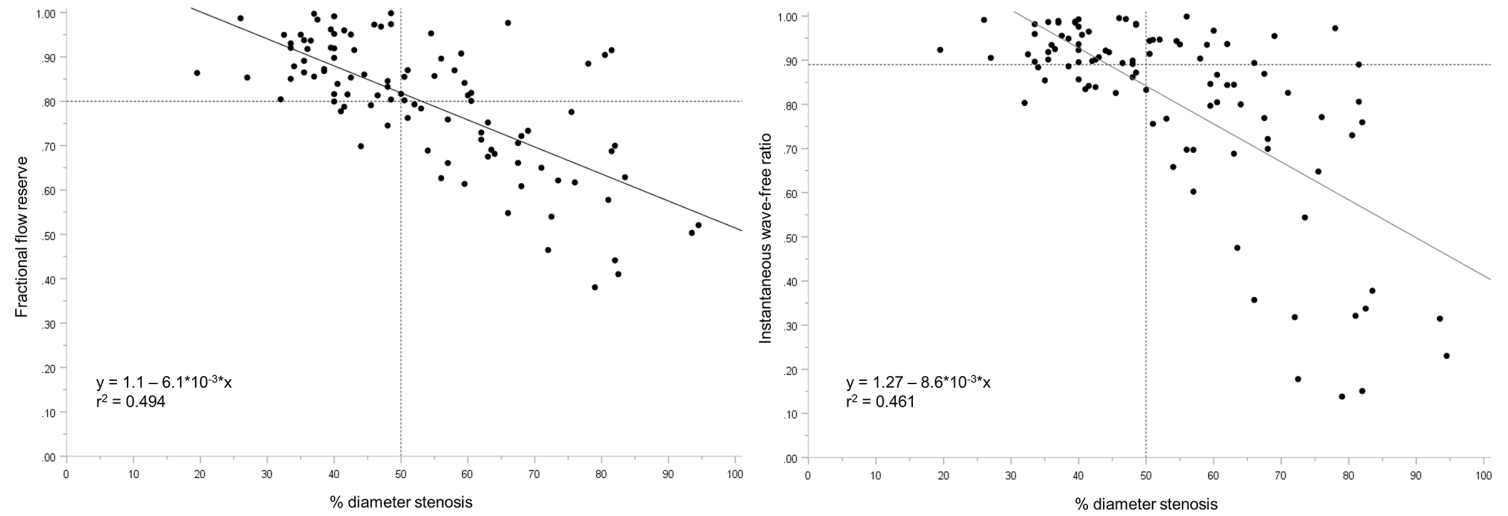

Figure 4 Linear regression between fractional flow reserve, respectively, instantaneous wave-free ratio and per cent diameter coronary stenosis. Solid lines=regression lines; dashed lines=common thresholds, that is, $\% \mathrm{~S} \geq 50 \%, \mathrm{FFR} \leq 0.80$, iFR $\leq 0.89$. $\% \mathrm{~S}$, per cent diameter stenosis; FFR, fractional flow reserve; iFR, instantaneous wave-free ratio.

Adverse events associated with dobutamine/atropine infusion were the following: one ventricular fibrillation requiring defibrillation (provoked by wedge position of the guiding catheter during maximal hyperemia), and two cases of supraventricular tachycardia (terminated during esmolol infusion at the end of the study protocol).

\section{DISCUSSION}

When tested against the structural parameter of per cent diameter coronary narrowing, haemodynamically relevant stenotic lesions are -overall- detected less accurately

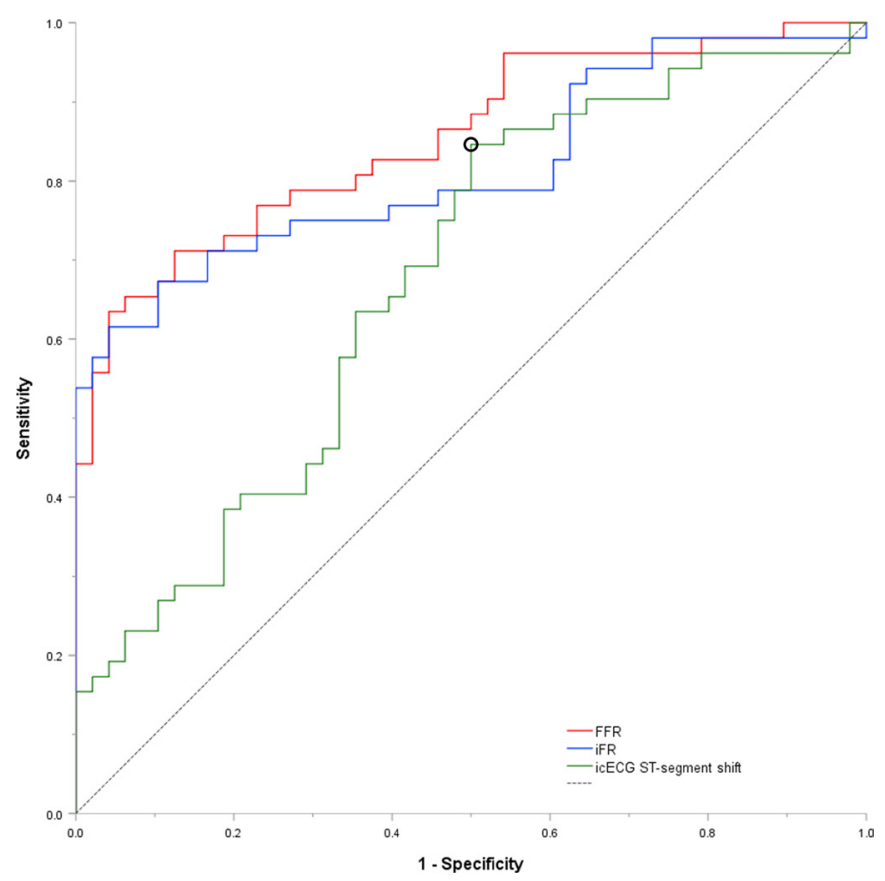

Figure 5 Non-parametric receiver-operating characteristic curve of intracoronary ECG (icECG) ST-segment shift, FFR and iFR, using a \%S threshold of $50 \%$ as structural significance definition. The black circle marks the best cut-off point for icECG ST-segment shift according to the YoudenIndex: $0.34 \mathrm{mV}$, sensitivity $85 \%$, specificity $50 \%$. \%S, per cent diameter stenosis; FFR, fractional flow reserve; iFR, instantaneous wave-free ratio. by icECG ST-segment shift during myocardial ischaemia than by hyperaemic FFR or diastolic wave-free coronary pressure ratio. The theoretically claimed stenosisspecificity of the pressure-derived functional indices was directly corroborated for the first time in our study, while icECG during hyperaemia very sensitively detected a relevant coronary stenosis responsible for myocardial ischaemia.

\section{icECG as direct indicator of myocardial physiology}

The ECG is essential in the diagnosis of myocardial ischaemia, the amount of which is a crucial prognostic factor. ${ }^{15}$ The commonly used surface ECG is, however, limited in detecting short-lasting or minor myocardial ischaemia. Conversely, due to its close vicinity to the myocardium, icECG is much more sensitive than surface ECG in detecting myocardial ischaemia. ${ }^{8}$ Thus, several clinical trials have assessed the value of icECG to guide PCI, and rated it useful to predict postprocedural myocardial injury. ${ }^{916}$

The detection of vasodilator-induced ischaemia by icECG is not unprecedented. Balian $e t a l^{11}$ compared icECG ST-segment shift during intravenous adenosine with FFR. Eighty-one per cent of the 48 patients with an FFR $\leq 0.80$ showed a significant icECG ST-segment shift during adenosine infusion, while $14 \%$ did so despite an FFR $>0.80$ (false positive cases). The major limitation of the study as stated by the authors was the induction of coronary perfusion heterogeneity by adenosine, that is, coronary steal. ${ }^{11}$ Hence, the use of dobutamine as a pharmacologic simulator of physical exercise with consecutive physiological hyperaemia might be preferable, since unmasking a haemodynamically relevant coronary stenosis does not require asymmetric stenosis distribution within the coronary tree as in the case of adenosineinduced hyperaemia.

Using dobutamine/atropine for ischaemia induction, icECG ST-segment shift showed a significant, but modest linear correlation with per cent diameter stenosis $\left(r^{2}=0.164\right.$, figure 3$)$. However, myocardial ischaemia, that is, the cause of icECG ST-segment shift, does not only 
depend on structural stenosis severity, but also on the area of ischaemic myocardium, and on the extent of coronary collateral blood supply. Accounting for these different determinants of ischaemia, the accuracy analysis results for icECG ST-segment shift is not surprising, showing a high sensitivity but a low specificity for structural stenosis relevance (figure 5). Hence, icECG could act as a rule out diagnostic test, that is, a functional test with high negative predictive value similar to the non-invasive coronary computed tomography angiography. Practically speaking, the presence of myocardial ischaemia on icECG with a ST-segment shift of $>0.34 \mathrm{mV}$ requires further structural and/or function assessment while the absence of ischaemia allows abstaining from further tests.

Aside from its high test sensitivity for detecting structurally relevant stenoses, icECG has a remarkable temporal sensitivity for dynamically changing ischaemia as illustrated by figure 2. IcECG as the vectored sum of energy dependant electrical processes in myocardial cells directly reflects the adequacy of myocardial perfusion, and is able to detect subtle voltage changes. Thus, in this patient with a haemodynamically significant coronary lesion $(\mathrm{FFR}=0.66, \mathrm{iFR}=0.76, \% \mathrm{~S}=68 \%)$, icECG recorded shortly after the start of the pharmacologic stress test showed subendocardial ischaemia. With progressive pharmacological stress, regional ischaemia extended across the myocardial wall. Transmural ischaemia, however, resolved quickly after termination of dobutamine infusion.

Taken together, for the detection of coronary structural (figure 5) as well as myocardial temporal supply (figure 2) changes, icECG is a highly sensitive instrument.

\section{Assessment of haemodynamic significance of epicardial coronary lesions}

Gould et al showed that epicardial coronary lesions cause diminished flow at rest once the arterial diameter reduction reaches $80 \%$, or $50 \%$ in case of maximal coronary blood flow. ${ }^{17}$ Thus, quantitative coronary angiography has offered a well-documented basis for revascularisation given a non-diseased reference diameter as obtained in more than one image projection. Yet, physician-based visual assessment with its notorious tendency to overestimate lesion severity remained the standard method instead of quantitative angiographic assessment for guiding revascularisation. ${ }^{18}$

Hence, to reduce unnecessary PCIs of coronary lesions, haemodynamic stenosis parameters have been introduced. FFR, which first has been validated against exercise stress testing to determine a cut-off value for inducible myocardial ischaemia $\left(\mathrm{FFR} \leq 0.66^{19}\right.$ ) has later been compared with various exercise stress tests, dobutamine stress echocardiography and myocardial perfusion imaging yielding a threshold for stenosis relevance of $0.75 .{ }^{5}$ In the subsequent FFR versus Angiography for Multivessel Evaluation (FAME-trials), a higher cut-off value of 0.80 has been selected based on the previously demonstrated practice of interventional cardiologists to perform PCI in the grey zone of $0.75-0.80 .{ }^{20}$ Among patients preselected for PCI by conventional visual (instead of quantitative) coronary angiographic assessment, the FAME-1 trial documented an advantage of angiography- plus FFR-guided versus angiography-guided PCI on major adverse cardiac events after 1 year. ${ }^{21}$

In theory, FFR has been thought to be stenosis-specific under the -uncertain- condition of adenosine-induced constant and minimal coronary arterial microcirculatory resistance. ${ }^{22}$ This concept has been mutually adopted based on an early study claiming FFR to be 'a lesionspecific index that reflects the effect of the epicardial stenosis on maximum myocardial perfusion'. ${ }^{22}$ In this regard, the present study's results corroborated for the first time the assumption of FFR's stenosis specificity, revealing specificity values of $96 \%$ for both FFR and iFR when tested against the truly structural quantitative parameter of $\% \mathrm{~S}$ (figure 5). Of note, the optimum cutoff value for FFR to detect a structural relevant stenosis of $\geq 50 \%$ diameter narrowing was 0.78 , thus demonstrating an almost perfect agreement with the commonly used FFR threshold of 0.80 .

More recently, a drug-free and thus more practical approach for haemodynamic stenosis assessment, iFR, has been introduced and compared with FFR, yielding good agreement between the two indices. ${ }^{6}$ In a subsequent clinical trial using a threshold of $\leq 0.89$, iFR has been proven non-inferior to FFR in guiding PCI. ${ }^{7}$ In regard to our study results, iFR showed an almost identical diagnostic performance to FFR with the same specificity, that is, demonstrating stenosis-specificity as well.

Nevertheless, both indices are affected by the distribution of coronary atherosclerotic disease, by asymmetrically distributed regional vascular resistances. This can only be accounted for by direct regional assessment of myocardial ischaemia as with icECG. In a broader sense and in the context of coronary blood flow as the source for the myocardium, ${ }^{4}$ icECG reflects the adequacy of regional myocardial perfusion.

\section{ECG and haemodynamic mismatch}

It is important to reiterate, that coronary pressure indices are not a true reference for myocardial ischaemia. Accordingly, a value below the threshold does not automatically represent myocardial ischaemia, but rather indicates a higher probability to induce myocardial ischaemia. Consequently, lesions with lower vs higher values benefit more from revascularisation as shown previously. ${ }^{23}$ The oversimplification of the relation between a coronary pressure ratio and myocardial ischaemia has been further demonstrated by the comparison of FFR and CFR, showing disagreement between the two methods in $40 \%$ of cases. ${ }^{24}$ There, the discrepancy has been assumed to be the result of variable stenosis morphology and its effect on coronary blood flow, that is, that focal atherosclerotic disease can cause a relevant pressure drop without relevant impairment of coronary blood flow. ${ }^{24}$

A similar situation was also encountered in the present study using the icECG as indicator for myocardial 
ischaemia. Applying a binary cut-off of $0.6 \mathrm{mV}$ for icECG, as derived from the surface ECG cut-off of $0.1 \mathrm{mV}$ and adjusted to the sixfold higher signal amplitude of the icECG, and an iFR cut-off of 0.89 , only $29 \%$ of the cases were concordant in demonstrating absent ischaemia, and $31 \%$ were concordant with ischaemia; $17 \%$ were discordant without ischaemia in the presence of focal disease, while $23 \%$ were discordant in the presence of diffuse or small-vessel disease. IcECG in combination with coronary pressure-derived indices allow comprehensive assessment of myocardial perfusion and thus, also an appraisal of the regional extent of atherosclerotic disease. Taken into account the results of the FAME-II-trial, where $80 \%$ of patients with abnormal FFR values did not experience cardiac events throughout the 2-year follow-up period, ${ }^{425}$ an optimal functional assessment should be preferred.

\section{Study limitations}

The major limitation of this study is the lack of information on cardiovascular outcome as a function of the amount of myocardial ischaemia by icECG ST-segment shift. Although myocardial ischaemia was proven several times as the principal predictor of cardiovascular outcome, ${ }^{15}$ its assessment would have increased the validity of the presented method. However, the present study was primarily designed to evaluate the interaction between structural and functional parameters of myocardial ischaemia. Thus, it would have been underpowered as an outcome trial.

Additionally, the employed stress test required an elaborated study protocol, which prolonged the assessment of coronary lesion severity. However, the observed high test sensitivity of icECG can be attributed to dobutamine/ atropine for ischaemia induction. In a post hoc analysis with assessment of the icECG ST-segment shift during reactive hyperaemia (that is, simultaneous assessment with the FFR), diagnostic performance shifted towards a higher specificity while completely losing sensitivity.

\section{Clinical implication}

IcECG is an easy to acquire parameter providing insight into myocardial physiology in real time with a fraction of the costs as it does not require expensive pressure monitoring angioplasty guidewires. Clinical application is, however, for a selected population with relative contraindications to PCI (for example bleeding history), where the prolonged measurement duration is out-weighed by the importance of accurate coronary lesion assessment. There, icECG can act as a high-sensitivity rule out test for relevant stenosis severity. Consequently, absence of ischaemia in the icECG during pharmacological inotropic stress represents maintained coronary blood flow and thus, PCI can be deferred. On the other hand, icECG ST-segment shift in combination with normal iFR may reflect diffuse epicardial or microvascular disease with a hampered vasodilator reserve capacity, in which case medical treatment would be indicated..$^{26}$

\section{CONCLUSION}

Hyperaemic icECG ST-segment shift detects structurally relevant coronary stenotic lesions with high sensitivity, while they are identified highly specific by FFR and iFR.

Twitter Marius Reto Bigler @biglermarius

Contributors MRB: data analysis, interpretation, drafting and revising of the manuscript; MS: conception and design, revising of the manuscript; FP, GCMS, RG, CT: data interpretation, revising the manuscript; CS: conception and design, data analysis, interpretation, drafting and revising of the manuscript.

Funding This study was supported by a grant from the Swiss Heart Foundation to MS.

Competing interests None declared.

Patient consent for publication Not required.

Ethics approval The study was approved by the Ethics Committee of the Canton of Bern, Switzerland (KEK-ID 2016-00726).

Provenance and peer review Not commissioned; externally peer reviewed.

Data availability statement The data, methods used in the analysis and materials used to conduct the research will be made available on reasonable request to any researcher for purposes of reproducing the results or replicating the procedure.

Open access This is an open access article distributed in accordance with the Creative Commons Attribution Non Commercial (CC BY-NC 4.0) license, which permits others to distribute, remix, adapt, build upon this work non-commercially, and license their derivative works on different terms, provided the original work is properly cited, appropriate credit is given, any changes made indicated, and the use is non-commercial. See: http://creativecommons.org/licenses/by-nc/4.0/.

ORCID iD

Marius Reto Bigler http://orcid.org/0000-0002-3199-4664

\section{REFERENCES}

1 Zbinden R, Zbinden S, Meier P, et al. Coronary collateral flow in response to endurance exercise training. Eur J Cardiovasc Prev Rehabil 2007;14:250-7.

2 Gould KL, Lipscomb K. Effects of coronary stenoses on coronary flow reserve and resistance. Am J Cardiol 1974;34:48-55.

3 van Nunen LX, Zimmermann FM, Tonino PAL, et al. Fractional flow reserve versus angiography for guidance of $\mathrm{PCl}$ in patients with multivessel coronary artery disease (FAME): 5-year follow-up of a randomised controlled trial. Lancet 2015;386:1853-60.

4 Stegehuis VE, Wijntjens GW, Piek JJ, et al. Fractional flow reserve or coronary flow reserve for the assessment of myocardial perfusion. Curr Cardiol Rep 2018;20:77.

5 Pijls NH, De Bruyne B, Peels K, et al. Measurement of fractional flow reserve to assess the functional severity of coronary-artery stenoses. N Engl J Med 1996;334:1703-8.

6 Sen S, Escaned J, Malik IS, et al. Development and validation of a new adenosine-independent index of stenosis severity from coronary wave-intensity analysis: results of the advise (adenosine vasodilator independent stenosis evaluation) study. J Am Coll Cardiol 2012;59:1392-402.

7 Davies JE, Sen S, Dehbi H-M, et al. Use of the instantaneous Wave-free ratio or fractional flow reserve in $\mathrm{PCI}$. $N$ Engl $\mathrm{J}$ Med 2017;376:1824-34.

8 Friedman PL, Shook TL, Kirshenbaum JM, et al. Value of the intracoronary electrocardiogram to monitor myocardial ischemia during percutaneous transluminal coronary angioplasty. Circulation 1986;74:330-9.

9 Balian V, Galli M, Marcassa C, et al. Intracoronary ST-segment shift soon after elective percutaneous coronary intervention accurately predicts periprocedural myocardial injury. Circulation 2006;114:1948-54.

10 de Marchi SF, Streuli S, Haefeli P, et al. Determinants of prognostically relevant intracoronary electrocardiogram STsegment shift during coronary balloon occlusion. Am J Cardiol 2012;110:1234-9.

11 Balian V, Marcassa C, Galli M, et al. Intracoronary electrocardiogram ST segment shift evaluation during intravenous adenosine infusion: a comparison with fractional flow reserve. Cardiol J 2011;18:662-7. 
12 Stoller M, Seiler C. Reactive myocardial hyperaemia for functional assessment of coronary stenosis severity. Eurolntervention 2017;13:e201-9.

13 Pijls NH, van Son JA, Kirkeeide RL, et al. Experimental basis of determining maximum coronary, myocardial, and collateral blood flow by pressure measurements for assessing functional stenosis severity before and after percutaneous transluminal coronary angioplasty. Circulation 1993;87:1354-67.

14 Vogel R, Zbinden R, Indermühle A, et al. Collateral-flow measurements in humans by myocardial contrast echocardiography: validation of coronary pressure-derived collateral-flow assessment. Eur Heart J 2006;27:157-65.

15 Hachamovitch R, Rozanski A, Shaw LJ, et al. Impact of ischaemia and scar on the therapeutic benefit derived from myocardial revascularization vs. medical therapy among patients undergoing stress-rest myocardial perfusion scintigraphy. Eur Heart $J$ 2011;32:1012-24.

16 Hishikari K, Yonetsu T, Lee T, et al. Intracoronary electrocardiogram ST-segment elevation in patients with non-ST-segment elevation myocardial infarction and its association with culprit lesion location and myocardial injury. Eurolntervention 2014;10:105-12.

17 Gould KL, Lipscomb K, Hamilton GW. Physiologic basis for assessing critical coronary stenosis. instantaneous flow response and regional distribution during coronary hyperemia as measures of coronary flow reserve. Am J Cardiol 1974;33:87-94.

18 Zhang H, Mu L, Hu S, et al. Comparison of physician visual assessment with quantitative coronary angiography in assessment of stenosis severity in China. JAMA Intern Med 2018;178:239-47.
19 De Bruyne B, Bartunek J, Sys SU, et al. Relation between myocardial fractional flow reserve calculated from coronary pressure measurements and exercise-induced myocardial ischemia. Circulation 1995;92:39-46.

20 Fearon WF, Tonino PAL, De Bruyne B, et al. Rationale and design of the fractional flow reserve versus angiography for multivessel evaluation (FAME) study. Am Heart J 2007;154:632-6.

21 Tonino PAL, De Bruyne B, Pijls NHJ, et al. Fractional flow reserve versus angiography for guiding percutaneous coronary intervention. N Engl J Med 2009;360:213-24.

22 Pijls NH, Van Gelder B, Van der Voort P, et al. Fractional flow reserve. A useful index to evaluate the influence of an epicardial coronary stenosis on myocardial blood flow. Circulation 1995;92:3183-93.

23 Johnson NP, Tóth GG, Lai D, et al. Prognostic value of fractional flow reserve: linking physiologic severity to clinical outcomes. J Am Coll Cardiol 2014;64:1641-54.

24 Johnson NP, Kirkeeide RL, Gould KL. Is discordance of coronary flow reserve and fractional flow reserve due to methodology or clinically relevant coronary pathophysiology? JACC Cardiovasc Imaging 2012;5:193-202.

25 De Bruyne B, Pijls NHJ, Kalesan B, et al. Fractional flow reserveguided $\mathrm{PCl}$ versus medical therapy in stable coronary disease. $N$ Engl J Med 2012;367:991-1001.

26 Lanza GA, Crea F. Primary coronary microvascular dysfunction: clinical presentation, pathophysiology, and management. Circulation 2010;121:2317-25 